\title{
EFICIÊNCIA PRODUTIVA DAS EMPRESAS PRESTADORAS DE SERVIÇOS DE ABASTECIMENTO DE ÁGUA E COLETA DE ESGOTO NAS CIDADES PAULISTAS
}

\author{
Productive Efficiency the Companies Providing Water Supply and Collection Sewage \\ Services in the São Paulo Cities
}

\author{
Ivan da Silva Melo ${ }^{1}$ \\ Diego Pierotti Procópio² \\ Adriel Rodrigues de Oliveira ${ }^{3}$ \\ Suely de Fátima Ramos Silveira ${ }^{4}$
}

Resumo: O presente trabalho tem como objetivo avaliar a eficiência produtiva das empresas prestadoras de serviços de abastecimento de água e coleta de esgoto nos municípios de São Paulo, devido à delimitação do problema de pesquisa e à disponibilidade de informações da base de dados do Sistema Nacional sobre Informações de Saneamento (SNIS). Para a realização do estudo foi utilizada a metodologia do DEA (Análise Envoltória de Dados), com modelo de retornos variáveis à escala e orientação produto. Os resultados apontaram para a necessidade de investimento tanto em infraestrutura quanto em modernização do setor produtivo das empresas que atuam no setor. Além disso, destaca-se a importância da entrada da iniciativa privada no setor, seja por meio de Parcerias Públicos - Privadas (PPP) ou de modo individual.

Palavras-chave: Saneamento Básico; Eficiência Produtiva; DEA.

Abstract: This study aims to evaluate the productive efficiency of companies providing water and sewage services in the municipalities of São Paulo, due to the delimitation of the research problem and the availability of information from the System National Information about Sanitation (SNIS). For the study we used the DEA methodology (Data Envelopment Analysis), model with variable returns to scale and product orientation. The results pointed to the need for investment both in infrastructure as in modernizing from sector productive the companies operating in the sector. In addition, we highlight the importance of the entry of the private sector in the sector, either through Public - Private Partnerships (PPP) or individually.

Keywords: Sanitation; Productive Efficiency; DEA.

JEL: L25

\footnotetext{
1 Especialista em Agronegócio. Mestrando em Administração e Bacharel em Gestão do Agronegócio pela Universidade Federal de Viçosa. ivansilva85@yahoo.com.br

${ }^{2}$ Mestre em Economia e bacharel em Gestão do Agronegócio, ambos pela Universidade Federal de Viçosa. Email: diego.procopio@ufv.br

3 Professor Associado do Departamento de Administração da Universidade Federal de Viçosa e Doutor em Administração pela Universidade de São Paulo. Email: aroli@ufv.br

${ }^{4}$ Professora Associada do Departamento de Administração da Universidade Federal de Viçosa e Doutor em Ciências pela Universidade de São Paulo. Email: sramos@ufv.br
} 


\section{INTRODUÇÃO}

O acesso aos serviços de saneamento básico é condição fundamental para a sobrevivência e dignidade humana. $O$ déficit na prestação dos serviços de abastecimento de água, coleta e tratamento de esgoto doméstico pode acarretar em graves problemas sociais para o Brasil, tanto para o setor de saúde pública, quanto para a preservação do meio ambiente que influencia diretamente na qualidade de vida de uma parte significativa da população brasileira (HUTTON; HALLER, 2004).

De acordo com o Ministério das Cidades (2015), o setor de saneamento básico no Brasil vem passando por grandes dificuldades. Em relação ao fornecimento de água, destaca-se o elevado nível de perdas, que chega ao patamar de $38,8 \%$ de toda a água produzida. $\mathrm{Na}$ coleta de esgoto, apenas $48,1 \%$ dos domicílios brasileiros possuem uma conexão com a rede de esgoto, ou seja, mais da metade das residências brasileiras lançam os dejetos em locais não apropriados, como por exemplo, em rios e mares. Para Sampaio e Sampaio (2007), o esgoto ao ser lançado no meio ambiente sem nenhum tipo de tratamento, além de representar um aumento da poluição humana à natureza, pode representar também um problema de saúde pública, com 0 aumento da proliferação de doenças de veiculação hídrica ${ }^{5}$.

Além disso, conforme observado por Sampaio e Sampaio (2007), a maior parte das externalidades negativas ocasionadas pela falta de infraestrutura adequada de saneamento básico no Brasil são em grande parte explicadas pela falta de investimentos e de uma política de regulação adequada ao setor.

Já que a deficiência da infraestrutura do setor de saneamento básico no país é um problema para ser resolvido no longo prazo, uma opção de curto prazo seria a melhoria do gerenciamento das empresas prestadoras de serviços de água e esgoto no país. Dessa forma, haveria uma melhora na utilização dos recursos disponíveis no país. Uma alternativa para se avaliar o desempenho produtivo de tais empresas, é o de verificar se elas estão sendo eficientes na utilização dos fatores de produção para a prestação de serviços nas cidades brasileiras (PROCÓPIO et al., 2014).

O objetivo deste estudo é analisar a eficiência produtiva das empresas prestadoras de serviços de abastecimento de água e coleta de esgoto de alguns municípios paulistas. Não foi possível selecionar todas as cidades localizadas no estado de São Paulo devido à limitação da base de dados. Para a realização do trabalho, foi utilizado o método de Análise Envoltória de Dados (DEA).

A análise congregou 221 das 645 cidades paulistas para o ano de 2012, sendo utilizada a base de dados do Sistema Nacional de Informações sobre Saneamento Básico (SNIS). A principal justificativa pela escolha do estado de São Paulo foi à disponibilidade de informações na base de dados e a crise no serviço de abastecimento de água que a unidade federativa vem passando atualmente. Adicionalmente, as empresas prestadoras de serviços de

\footnotetext{
${ }^{5}$ De acordo com a Organização Mundial de Saúde (2015), aproximadamente 80 tipos de doenças podem ser transmitidos ao ser humano a partir do contato com água contaminada.
} 
saneamento básico foram analisadas de acordo com a natureza jurídica da gestão administrativa: administração pública direta, autarquia, empresa privada, empresa pública e sociedade de economia mista com a administração pública.

$\mathrm{Na}$ próxima seção são relatadas algumas considerações sobre regulação no setor de saneamento básico. Em sequência, na terceira seção é apresentado o procedimento metodológico utilizado e, por fim, nas duas últimas seções são discutidos os principais resultados e as considerações finais do estudo.

\section{REGULAÇÃO NO SETOR DE SANEAMENTO BÁSICO}

No setor de saneamento básico, a existência de concorrência é inviável. Não é eficaz no sentido econômico nem no sentido espacial a existência de duas empresas atuando no fornecimento de água e coleta de esgoto em uma mesma cidade (MADEIRA, 2004). Para Jouravlev (2004) são três as razões que tornam o setor integrado verticalmente por uma mesma empresa, sendo: (i) impossibilidade de competição em qualquer estágio do processo de produção; (ii) a integração vertical gera consideráveis economias de escopo (já que a estrutura de distribuição de água é utilizada para o tratamento e coleta de esgoto); e, (iii) tem-se dificuldade de se taxar as diferentes etapas da produção.

O setor de saneamento básico possui algumas características peculiares que o difere de outros setores de infraestrutura (como o elétrico e o de telecomunicações) e são apresentadas no Quadro 1.

De acordo com Jouravlev (2004), já que apenas uma empresa atua em todo o processo produtivo das empresas de saneamento básico em um município, tanto no abastecimento de água e coleta de esgoto, o setor é caracterizado como um Monopólio Natural ${ }^{6}$. Nesse caso, a demanda é inelástica ${ }^{7}$ e não há ameaça de competição, então as empresas prestadoras de serviço de saneamento não possuem qualquer incentivo em reduzir os custos ou de melhorar a eficiência produtiva.

Por outro lado, a universalidade do atendimento, relacionada ao caráter essencial da prestação dos serviços de saneamento, independe da capacidade de pagamento dos usuários. Com isso, o poder de monopólio se contrapõe ao caráter essencial dos serviços, sendo assim, é necessária a regulação para que se possa garantir o equilíbrio entre produtores e consumidores (FARINA; AZEVEDO; PICCHETTI, 1997).

\footnotetext{
${ }^{6}$ O Monopólio é considerado uma estrutura de mercado que possui por características básicas a presença de apenas uma empresa atuando no setor econômico em questão e a existência de barreiras à entrada (que podem ser de ordem tecnológica ou institucional) de novas empresas na atividade econômica em que a firma monopolista atua (VARIAN, 2003).

${ }_{7}^{7} \mathrm{~A}$ demanda inelástica ocorre quando uma variação do preço de um bem ou serviço resulta numa variação muito menor na quantidade demandada desse mesmo bem ou serviço, isso num determinado período de tempo. A lei da Demanda determina que quando o preço de um bem ou serviço diminui, a quantidade demandada por esse bem ou serviço aumenta e a situação inversa também é válida (VARIAN, 2003).
} 
A Lei número $11.445 / 2007^{8}$, conhecida como a "Lei do Saneamento", trata da questão regulatória no setor de saneamento básico no Brasil. Para Galvão Junior e Paganini (2009), a regulação pode ser entendida como uma intervenção do Estado nas ordens econômica e social em setores estratégicos, com a finalidade de propiciar eficiência e equidade, traduzidas como a universalização na provisão de bens e serviços públicos essenciais para 0 bem-estar da população de uma nação.

\section{Quadro 1 - Características do setor de saneamento básico}

\begin{tabular}{|c|c|c|}
\hline \multicolumn{2}{|r|}{ Características } & Repercussões \\
\hline \multirow{5}{*}{$\frac{\mathscr{D}}{\mathscr{J}}$} & $\begin{array}{lr}\text { Maioria } & \text { de ativos } \\
\text { (redes de água e } \\
\text { esgoto) encontra-se } \\
\text { enterrada }\end{array}$ & $\begin{array}{l}\text { Difícil determinação do estado de conservação, custo } \\
\text { de manutenção elevado e complexidade para } \\
\text { detecção de vazamentos nas tubulações. }\end{array}$ \\
\hline & $\begin{array}{l}\text { Mudança lenta no } \\
\text { padrão tecnológico }\end{array}$ & $\begin{array}{l}\text { Poucos ganhos de eficiência mediante avanços } \\
\text { tecnológicos e ativos com vida útil prolongada. }\end{array}$ \\
\hline & $\begin{array}{l}\text { Qualidade dos produtos } \\
\text { de r complexa } \\
\text { verificação pelo usuário }\end{array}$ & $\begin{array}{l}\text { Necessidade de estrutura adequada para } \\
\text { monitoramento da qualidade de produtos e serviços } \\
\text { ofertados pelas concessionárias. }\end{array}$ \\
\hline & $\begin{array}{l}\text { Redes integradas em } \\
\text { aglomerados urbanos }\end{array}$ & $\begin{array}{l}\text { Envolvimento de mais de um ente federado na } \\
\text { gestão dos serviços e expansão da infraestrutura } \\
\text { associada ao planejamento urbano. }\end{array}$ \\
\hline & $\begin{array}{l}\text { Essencialidade no uso } \\
\text { e consumo de produtos } \\
\text { (água e esgoto) }\end{array}$ & $\begin{array}{l}\text { Atendimento independente da capacidade de } \\
\text { pagamento do usuário e geração de externalidades } \\
\text { positivas e negativas para a saúde pública, meio } \\
\text { ambiente, recursos hídricos, dentre outros. }\end{array}$ \\
\hline \multirow{6}{*}{ 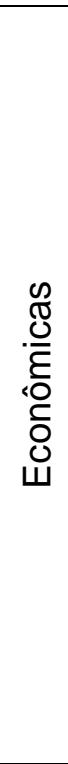 } & Custo fixo elevado & $\begin{array}{l}\text { Pouca flexibilidade para a periodização dos } \\
\text { investimentos. }\end{array}$ \\
\hline & $\begin{array}{l}\text { Ativos específicos e de } \\
\text { longa maturação }\end{array}$ & $\begin{array}{l}\text { Monopólio natural; inexistência de usos alternativos e } \\
\text { baixo valor de revenda; possibilidade remota de } \\
\text { saída das concessionárias do mercado (não } \\
\text { contestável); e, pouca atividade para investimentos. }\end{array}$ \\
\hline & $\begin{array}{l}\text { Assimetria } \\
\text { informações }\end{array}$ & $\begin{array}{l}\text { Demais atores do setor dependem da informação } \\
\text { técnica e econômico-financeira disponibilizada pelas } \\
\text { concessionárias. }\end{array}$ \\
\hline & Demanda inelástica & $\begin{array}{l}\text { Possibilidade de extração de renda significativa pelo } \\
\text { prestador de serviços (monopólio). }\end{array}$ \\
\hline & Economias de escala & $\begin{array}{l}\text { Viabilidade da prestação dos serviços por uma única } \\
\text { empresa (monopólio). }\end{array}$ \\
\hline & Economias de escopo & $\begin{array}{l}\text { Custos comuns na operação de serviços de água e } \\
\text { esgoto e tratamento de esgotos, tornando mais } \\
\text { viável a prestação dos serviços por uma única } \\
\text { empresa. }\end{array}$ \\
\hline
\end{tabular}

Fonte: (GALVÃO JUNIOR; PAGANINI, 2009).

\footnotetext{
${ }^{8}$ A lei definiu instrumentos e regras para o planejamento, a fiscalização, a prestação e a regulação dos serviços prestados à população. A implantação da regulação no setor de água e esgoto apresenta enormes desafios, além do déficit de infraestrutura, há também a falta de capacidade político-administrativa no gerenciamento das empresas prestadoras de serviços de água e esgoto à população (GALVÃO JUNIOR; PAGANINI, 2009).
} 
No caso de ocorrência da regulação estabelecida pela "Lei do Saneamento", uma série de benefícios poderia acontecer no setor de saneamento básico brasileiro, que são: (i) a geração de incentivos para práticas eficientes de gestão, expansão do produto e redução de tarifas; (ii) a maximização da qualidade dos serviços e alavancamento dos investimentos, com vista na modernização do setor e universalização dos serviços; (iii) o favorecimento da adoção de uma gestão profissional e a autonomia administrativa das empresas públicas; (iv) a limitação da interferência política no setor mediante regras implementadas independentemente do ciclo eleitoral; e, (v) a garantia de universalização dos serviços de saneamento e assim evitar que ocorra uma taxação excessiva aos consumidores pela prestação de serviços (SEROA DA MOTTA, 2006; CONFORTO, 2000; BRITTO, 2001).

Dessa forma, o setor de saneamento básico apresenta características essenciais que se contrapõem. De um lado, o aspecto econômico cuja empresa Monopolista não possui incentivos para a expansão do serviço e nem pela busca da eficiência produtiva e, de outro, o caráter essencial do setor que afeta diretamente o bem-estar da sociedade brasileira. Sendo assim, atribui-se a importância da intervenção governamental que foi iniciada pela "Lei do Saneamento" que possui por objetivo central o de melhorar a prestação de serviços de abastecimento de água e coleta de esgoto nos municípios brasileiros.

\section{PROCEDIMENTOS METODOLÓGICOS - ANÁLISE ENVOLTÓRIA DE DADOS (DEA)}

A metodologia DEA é uma técnica não paramétrica baseada na programação matemática, em que a medida de eficiência gerada é relativa, ou seja, é dependente da base de dados utilizada. Além disso, na literatura relacionada aos modelos de DEA, uma unidade produtiva analisada é tratada como uma DMU (decision making unit) (FERREIRA; GOMES, 2009).

Basicamente, a eficiência pode ser separada em dois componentes: a eficiência técnica e a eficiência alocativa. A primeira reflete a habilidade de uma unidade produtiva em obter o máximo produto, dado um conjunto de insumos. Já, o segundo tipo de eficiência reflete a habilidade da unidade de produção em utilizar os insumos em proporções ótimas, de acordo com os preços relativos dos fatores de produção. A combinação destas duas medidas de eficiência fornece a eficiência econômica total (FERREIRA; GOMES, 2009).

Nos modelos DEA, dois tipos de orientação podem ser seguidos de acordo com as medidas de eficiência: $1^{a}$ ) orientação produto, que dá ênfase no aumento do produto mantendo-se fixos os insumos; e, $2^{\mathrm{a}}$ ) orientação insumo, que se baseia na redução da utilização dos insumos, para dado nível de produção já definido. No presente trabalho, utilizou-se a orientação produto, pois é desejável expandir o atendimento de serviços de abastecimento de água e de coleta de esgoto à população das cidades analisadas, dada a disponibilidade de recursos das empresas prestadoras desses serviços. 
Uma pressuposição fundamental na técnica DEA é que, se uma empresa (A) prestadora de serviço de água e esgoto é capaz de ofertar $Y(A)$ unidades de serviços de saneamento, utilizando $X(A)$ unidades de recursos, outras também podem fazer o mesmo, caso estejam operando eficientemente. Desse modo, conforme relatado por Ferreira e Gomes (2009), as empresas classificadas como eficientes são consideradas benchmarks para as ineficientes, servindo de referência por apresentarem uma melhor utilização dos recursos disponíveis.

Os modelos DEA podem assumir tanto retornos constantes como retornos variáveis à escala de produção ${ }^{9}$. Este estudo considerará que há retornos variáveis à escala. Tal modelo foi proposto por Banker, Charnes e Cooper (1984) e é apresentado de acordo com o seguinte problema de programação matemática, representada por meio da equação 1.

$$
\begin{gathered}
\operatorname{MAX}_{\theta, \lambda} \phi \\
\text { sujeito a } \\
-\phi \mathrm{y}_{\mathrm{i}}+\mathrm{Y} \lambda \geq 0 \\
\mathrm{x}_{\mathrm{i}}-\mathrm{X} \lambda \geq 0 \\
\mathrm{~N}_{1}^{*} \lambda=1 \\
\lambda \geq 0
\end{gathered}
$$

Em que $N_{1} \lambda^{\prime}=1$ é uma restrição de convexidade e $N_{1}$ é um vetor de algarismos unitários na ordem de $(n \times 1)$. A medida $1 / \phi$ representa a eficiência técnica que varia no intervalo de zero a um. Já $\phi$ varia no intervalo de $1 \leq \phi \leq{ }^{\infty}$ e que $\phi-1$ corresponde ao aumento proporcional no produto considerado, mantendo-se a constante utilização dos insumos em questão. $O$ parâmetro $\lambda$ é um vetor ( $n \times 1)$, cujos valores são calculados de forma a obter uma solução ótima. Para uma DMU eficiente, todos os valores de $\lambda$ serão zero, enquanto que para uma DMU ineficiente, os valores desse parâmetro serão os pesos utilizados na combinação linear de outras DMU's eficientes que influenciam a projeção da ineficiente sobre a fronteira calculada.

Além disso, o modelo com retornos variáveis corresponde a uma medida de eficiência técnica pura, uma vez que está depurado dos efeitos de escala de produção. Para a obtenção do valor da medida de eficiência de escala das empresas que provêm o abastecimento de água e coletam o esgoto nas cidades paulistas analisadas, tem-se a equação 2 apresentada a seguir, sendo que tal fórmula foi extraída do estudo de Ferreira e Gomes (2009).

$$
\text { Eficiência } a_{\text {escala }}=\frac{\text { Eficiência Técnica }{ }_{\text {retornos constantes }}}{\text { Eficiência Técnica }}
$$

\footnotetext{
${ }^{9}$ De acordo com Varian (2003) a Economia de Escala podem apresentar três tipos de retornos, que são: (i) Constante - ocorre quando todas as unidades do fator variável que for aplicado ao fator fixo no sistema produtivo da empresa resultar em aumentos iguais no total de produção obtida; (ii) Decrescente - ocorre quando cada nova unidade do fator variável que for aplicada ao fator fixo aumentar menos a produção total que a unidade anterior; e, (iii) Crescente ocorre quando cada unidade nova do fator variável que for aplicada ao fator fixo aumentar mais a produção total do que a unidade anterior.
} 
Para a realização desta parte do estudo, foram consideradas como input as seguintes variáveis: número de empregados (X1); extensão da rede de água (X2); e, extensão da rede de esgoto (X3). Já as variáveis output foram: população total atendida com água (Y1); quantidade de ligações ativas de água (Y2); população total atendida com esgotamento sanitário (Y3); e, quantidade de ligações ativas de esgoto (Y4). Essas variáveis foram selecionadas com 0 intuito de avaliar quais das empresas são mais eficientes na prestação dos serviços de saneamento básico de acordo com a infraestrutura produtiva disponível.

A base de dados utilizada nesta pesquisa foi a do Sistema Nacional de Informações sobre Saneamento (SNIS). Nesta fonte de informações encontram-se operacionais e administrativas de empresas prestadoras de serviços de saneamento básico que atuam em diversas cidades brasileiras. No presente trabalho foram selecionadas as empresas que atuam nas cidades paulistas para o ano de 2012, que foi o período mais recente quando foi realizado este estudo.

\section{RESULTADOS E DISCUSSÃO}

As empresas de saneamento básico analisadas variam de acordo com a natureza jurídica, sendo elas gerenciadas pela Administração Pública Direta, Autarquias, Empresas Públicas, Empresas Privadas e Sociedades Mistas com Administração Pública (Tabela 1). Além disso, tais empresas atuam apenas nos municípios em que estão localizadas as sedes administrativas, que totalizam 221 empresas, que são apresentadas de forma detalhada na Tabela $1 \mathrm{~A}$ do apêndice 1 .

De acordo com as informações da Tabela 1, tem-se que na maior parte dos municípios analisados, as empresas prestadoras de serviços de saneamento são geridas principalmente pelas prefeituras e autarquias. Desse modo, por meio da Tabela 2 são apresentados os resultados de eficiência técnica pura e o tipo de retorno à escala das empresas, de acordo com o tipo de gestão, como forma de conferir tipo de gestão administrativa apresenta um melhor desempenho produtivo.

Ferreira e Gomes (2009) observam que a melhor condição operacional de uma empresa ocorre quando esta é eficiente na utilização dos fatores produtivos e opera com retornos constantes à escala, ou seja, nesta situação a firma estará utilizando os recursos sem desperdícios e em escala ótima de produção. Dessa forma, a partir das informações da Tabela 2, do total de 221 empresas analisadas, apenas 10 empresas são eficientes produtivamente e operam em escala ótima, com retornos constantes.

Quando se analisa o desempenho das empresas privadas atuantes na prestação de serviços de abastecimento de água e coleta de esgoto nas cidades paulistas selecionadas, apenas uma empresa foi eficiente, porém obteve retornos crescentes de escala. Essa empresa atua no município de Mirassol, cidade com população de 57.390 habitantes, considerada de 
pequeno a médio porte. Vargas (2005) enfatiza que a concessão de serviços de água e esgotamento sanitário para a iniciativa privada pode ser uma alternativa viável para expandir e melhorar a eficiência em empresas de cidades de médio e grande porte, pois trabalham em condições institucionais que permitem assegurar a regulação e o controle sobre o setor.

Tabela 1 - Quantidade e informações das empresas prestadoras de serviços de saneamento de acordo com a natureza jurídica nos municípios paulistas analisados

\begin{tabular}{|c|c|c|}
\hline Tipo de empresa & Quantidade & Informações \\
\hline $\begin{array}{l}\text { Administração } \\
\text { Pública Direta }\end{array}$ & 130 & $\begin{array}{l}\text { Secretarias, departamentos ou outros } \\
\text { órgãos da administração pública direta. }\end{array}$ \\
\hline Autarquia & 74 & $\begin{array}{l}\text { Entidade com personalidade jurídica de } \\
\text { direito público, criada por lei específica, } \\
\text { com patrimônio próprio, atribuições públicas } \\
\text { específicas e capacidade de auto } \\
\text { administrar-se sob controle federal, } \\
\text { estadual ou municipal. }\end{array}$ \\
\hline Empresa Privada & 13 & $\begin{array}{l}\text { Empresa com capital predominante ou } \\
\text { integralmente privado, administrada } \\
\text { exclusivamente por particulares. }\end{array}$ \\
\hline Empresa Pública & 1 & $\begin{array}{l}\text { Entidade para - estatal, criada por lei, com } \\
\text { personalidade jurídica de direito privado, } \\
\text { com capital exclusivamente público, de uma } \\
\text { só ou de várias entidades, mas sempre } \\
\text { capital público. }\end{array}$ \\
\hline $\begin{array}{l}\text { Sociedade de } \\
\text { Economia Mista } \\
\text { com Adm. Pública }\end{array}$ & 3 & $\begin{array}{l}\text { Entidade paraestatal, criada por lei, com } \\
\text { capital público e privado, maioria pública } \\
\text { nas ações com direito a voto, gestão } \\
\text { exclusivamente pública, com todos os } \\
\text { dirigentes indicados pelo poder público. }\end{array}$ \\
\hline TOTAL & 221 & \\
\hline
\end{tabular}

Fonte: Elaborado a partir de informações da SNIS (2015).

Portanto, a participação de empresas privadas no setor de saneamento básico pode contribuir para ampliação e melhoraria da cobertura e qualidade dos serviços prestados. Nesta discussão, Melo e Neto (2007) avaliam que a prestação de serviços de saneamento básico é financeiramente superavitária em municípios com mais de 100 mil habitantes, ou seja, em municípios de pequeno e médio porte a iniciativa privada não encontra incentivo para gerirem os serviços de abastecimento de água e coleta de esgoto.

Tal constatação é relatada por Jouravlev (2004), o autor relata que as características do setor analisado, de elevada necessidade de investimentos em infraestrutura para expansão de serviços de atendimento a população desestimulam a entrada da iniciativa privada, fazendo-se necessária a intervenção Estatal na concessão de garantias para que as empresas privadas invistam nas atividades de prestação de serviços de tratamento de água e esgoto, tanto no estado de São Paulo quanto no Brasil. 
Quando analisadas as empresas por tipo de natureza jurídica, numa comparação entre as empresas da administração pública direta e autarquias, que compõem a maior parte da amostra analisada, as empresas geridas pelas prefeituras dos municípios apresentam resultados inferiores em termos de eficiência técnica pura (Tabela 2).

Tabela 2 - Quantidade de empresas prestadoras de serviços de saneamento dos municípios paulistas, segundo o grau de eficiência, 0 tipo de retorno à escala e a natureza jurídica

\begin{tabular}{l|c|c|c|c|c}
\hline \multirow{2}{*}{$\begin{array}{l}\text { Tipo } \\
\text { Empresa }\end{array}$} & \multicolumn{2}{|c|}{$\begin{array}{c}\text { Eficiência Técnica } \\
\text { Pura }\end{array}$} & \multicolumn{3}{c}{ Tipo de retorno à escala } \\
\cline { 2 - 6 } & Eficiente & Ineficiente & Crescente & Constante & Decrescente \\
\hline $\begin{array}{l}\text { Adm. Pública } \\
\text { Direta }\end{array}$ & 12 & 118 & 71 & 5 & 54 \\
\hline Autarquia & 9 & 65 & 35 & 3 & 36 \\
\hline $\begin{array}{l}\text { Empresa } \\
\text { Privada }\end{array}$ & 1 & 12 & 9 & 1 & 3 \\
\hline $\begin{array}{l}\text { Empresa } \\
\text { Pública }\end{array}$ & 0 & 1 & 1 & 0 & 0 \\
\hline $\begin{array}{l}\text { Sociedade } \\
\text { de Eco.Mista } \\
\text { com Adm. } \\
\text { Pública }\end{array}$ & 1 & 2 & 2 & 1 & 0 \\
\hline
\end{tabular}

Fonte: Resultado da Pesquisa.

Neste sentido, Vargas (2005) ressalta que a capacidade de investimentos dos operadores públicos é frequentemente comprometida pela ineficiência na gestão dos serviços, que muito das vezes são vulneráveis por interferências políticas e desvios de recursos para outras finalidades públicas. Nozaki (2007) ainda enfatiza que cada tipo de empresa que presta o serviço de saneamento apresenta características peculiares de gestão que as diferenciam em vários aspectos, tais como as formas de fiscalização, atribuição de deveres e responsabilidades, dentre outros fatores que exercem influencia no desempenho dos prestadores de serviços de abastecimento de água e coleta de esgoto.

Analisando as empresas de economia mista com administração pública, coube destacar o rendimento da empresa operante no município de Diadema, única prestadora de serviços que foi eficiente na utilização dos recursos produtivos (Tabela 2). Em relação à empresa pública presente na amostra selecionada, observou-se que esta opera em níveis de ineficiência com retornos crescentes de escala. Diante disso, Vargas (2005) avalia a importância da adoção de parcerias público-privadas (PPP), argumentando que tais parcerias possam estimular ocorrência de feedbacks entre as partes envolvidas contribuindo na melhoria do desempenho na prestação de serviços que envolvem o setor.

Outra questão importante a se discutir é relacionada aos tipos de retornos de escala em que a maior parte das empresas prestadoras de serviços de abastecimento de água e coleta de esgoto está operando. As empresas que são geridas pelas prefeituras, em sua maior parte estão 
operando com retornos crescentes de escala. Já as autarquias se concentram principalmente nos retornos crescentes e decrescentes. A maioria das empresas privadas operam com retornos crescentes, a mesma situação é recorrente quando analisadas as empresas públicas e de economia mista com a administração pública (Tabela 2). Esse resultado mostra que na maioria das empresas analisadas que não há um gerenciamento adequado quanto à escala de produção da firma.

Ferreira e Gomes (2009) afirmam que há retornos crescentes de escala, se acréscimos no consumo de recursos implicarem em um aumento mais que proporcional na quantidade de produtos gerados, com isso, é possível um ganho na expansão da produção por meio das economias de escalas. Neste caso, não existem insumos sendo utilizados em excesso, mas o volume de produção encontra-se abaixo da escala ótima. Diante disso, é possível que se aumente o abastecimento de água e coleta de esgoto das empresas sem comprometer o desempenho produtivo, possibilitando assim uma expansão da prestação de serviços de saneamento básico nas cidades analisadas.

No caso específico das autarquias, dos quais a maior parte das empresas atuam com retornos decrescentes de escala, Ferreira e Gomes (2009) observam que é recomendável que as empresas diminuam o volume de produção ou adotem algum tipo de inovação tecnológica que proporcione um aperfeiçoamento do sistema produtivo. Esse resultado mostra a importância do investimento em infraestrutura e também na modernização das empresas que atuam no setor de saneamento básico nas cidades paulistas e também no restante do país. Tal resultado veio de encontro à discussão apresentada no estudo de Procópio et al. (2014) que ao analisarem algumas cidades mineiras constataram a importância de investimento no setor.

\section{Tabela 3 - Medidas Descritivas da Eficiência Produtiva das Empresas} Analisadas

\begin{tabular}{l|c|c|c}
\hline Empresa & Média & Mínimo & Máximo \\
\hline Administração Pública Direta & 0,69 & 0,32 & 1,00 \\
\hline Autarquia & 0,66 & 0,27 & 1,00 \\
\hline Empresa Privada & 0,80 & 0,56 & 1,00 \\
\hline Empresa Pública de Economia Mista com & 0,67 & 0,67 & 0,67 \\
\hline $\begin{array}{l}\text { Sociedade de } \\
\text { Administração Pública }\end{array}$ & $\mathbf{0 , 6 8}$ & $\mathbf{0 , 2 7}$ & $\mathbf{1 , 0 0}$ \\
\hline Total & &
\end{tabular}

Fonte: Resultado da Pesquisa

$\mathrm{Na}$ Tabela 3 são apresentadas as medidas descritivas da eficiência produtiva das empresas que compõem a amostra, como forma de avaliar quais empresas apresentam as melhores médias de eficiência técnica pura.

De acordo com a Tabela 3, as empresas administradas pelo setor privado apresentam o maior valor médio de eficiência técnica pura quando comparadas com os outros tipos de empresas que atuam no setor. Esse resultado pode estar indicando que na iniciativa privada a gestão de recursos ocorre de melhor forma do que no setor público. 
A segunda maior média foi alcançada pelas Sociedades de Economia Mista com Administração Pública. Este resultado pode indicar a vantagem das parcerias público-privadas em relação à forma de gestão dos recursos disponíveis para a prestação dos serviços de saneamento básico, podendo levar em consideração nessa situação à experiência da iniciativa privada na forma de gerenciar os fatores produtivos em uma empresa.

Além disso, por meio da Lei número 11.079 de 30 de dezembro de 2004, estabelece que através da efetivação da parceria público-privada os serviços prestados devem ser realizados com eficiência no cumprimento das missões do Estado e no emprego dos recursos disponíveis na sociedade, ou seja, enfatiza a importância da preocupação do bem-estar da população brasileira, bem como com o aspecto econômico da utilização adequada dos fatores de produção que são utilizados para a prestação de serviços de abastecimento de água e coleta de esgoto.

Ainda em relação às médias de eficiência, o pior resultado foi alcançado pelas autarquias, pois apresentaram o menor valor médio de eficiência técnica pura. Indicando assim, que dentre os tipos de empresas analisadas, o tipo de gestão realizado pelas empresas autárquicas se mostrou as mais ineficientes.

\section{CONSIDERAÇÕES FINAIS}

A análise de eficiência produtiva das empresas prestadoras de serviços de abastecimento de água e coleta de esgoto das empresas de saneamento no Estado de São Paulo mostra-se de grande importância para o desenvolvimento do setor, pois possibilita um maior conhecimento sobre quais empresas estão sendo mais eficientes na utilização dos recursos, servindo de auxílio nas tomadas de decisões sobre políticas públicas que possam impactar em investimentos no setor que contribuam para a melhoria da eficiência das empresas permitindo-as elevar os níveis de prestação de serviços de abastecimento de água e coleta de esgoto contribuindo desta forma para 0 processo de universalização de acesso aos serviços de saneamento básico no Estado.

Numa visão de curto prazo, é necessária a elaboração de políticas públicas que venham a promover a capacitação administrativa e técnicooperacional dos funcionários de tais empresas, visto que, parte significativa das cidades analisadas está operando em escalas decrescentes de produção. Já numa visão de longo prazo deve-se focar em políticas públicas que invistam em infraestrutura urbana, principalmente, nos municípios de pequeno e médio porte, para que parte das empresas que operam com escalas crescentes possam expandir a produção com ganhos de economias de escala, possibilitando maior acesso aos serviços de tratamento de água e coleta de esgoto. Vale citar, por exemplo, políticas públicas como o de disponibilidade de recursos do BNDES (Banco Nacional de Desenvolvimento Econômico e Social) para as empresas prestadoras de serviços de saneamento básico e também cursos técnicos de capacitação oferecidos por entidades como o SENAI 
(Serviço Nacional de Aprendizagem Industrial) para os funcionários destas empresas.

Destaca-se também a importância de parcerias do setor público com a iniciativa privada para o gerenciamento dos serviços de saneamento básico nas cidades do estado paulista e também no restante do país. Outra pesquisa que poderia ser realizada é a comparação da eficiência produtiva entre as empresas prestadoras de serviços de saneamento básico de abrangência local (geralmente administradas pelas prefeituras, autarquias e empresas privadas) com as de abrangência regional (empresas ligadas às Companhias de Saneamento Básico Estadual), que no caso do estado de São Paulo é representado pela SABESP (Companhia de Saneamento Básico do Estado de São Paulo).

\section{REFERÊNCIAS}

BANKER, R. D., CHARNES, H., COOPER, W. W. Some models for estimating technical and scale inefficiencies in data envelopment analysis. Management Science, v. 30, n. 9, p. 1078-1092, 1984.

BRASIL. Lei número 11.079 de 30 de dezembro de 2004. Disponível em:< http://www.planalto.gov.br/ccivil_03/_ato2004-2006/2004/lei/111079.htm>.

Acesse em: 02 abr. 2015.

BRITTO, A. L. N. P. A Regulação dos serviços de saneamento no Brasil: perspectiva histórica, contexto atual e novas exigências de uma regulação pública. In: ENCONTRO NACIONAL DA ANPUR, 9, 2001, Rio de Janeiro. Anais... Rio de Janeiro: ANPUR, 2001.

CONFORTO, G. A regulação e a titularidade dos serviços de abastecimento de água e esgotamento sanitário no Brasil. Revista de Administração Pública, v. 34, n. 5, p. 165-80, 2000.

FARINA, E. M. M. Q.; AZEVEDO, P. F.; PICCHETTI, P. A reestruturação dos setores de infraestrutura e a definição dos marcos regulatórios: princípios gerais, características e problemas. Brasília: Instituto de Pesquisa Econômica Aplicada, 1997.

FERREIRA, C. M. C., GOMES, A. P. Introdução à análise envoltória de dados: teoria, modelos e aplicações. Viçosa: Editora UFV, 2009.

GALVÃO JUNIOR, A. C.; PAGANINI, W. S. Aspectos conceituais da regulação dos serviços de água e esgoto no Brasil. Revista de Engenharia Sanitária Ambiental, v. 14, n. 1, p. 79-88, 2009.

HUTTON, G.; HALLER, L. Evaluation of the costs and benefits of water and sanitation improvements at the global level. Genebra: Organização Mundial da Saúde, 2004.

JOURAVLEV, A. Drinking water supply and sanitation services on the threshold of the XXI century. Santiago do Chile: Cepal, 2004. 
MADEIRA, R. F. O setor de saneamento básico no Brasil e as implicações do marco regulatório para a universalização do acesso. Revista do BNDES, n. 33, p. 123-154, 2004.

MELO, J. A. M.; NETO, P. M. J. Bem-estar social, regulação e eficiência no setor de saneamento básico. In: XXXV Encontro Nacional de Economia, 35, 2007, Recife. Anais... Recife: Encontro Nacional de Economia, 2007.

MINISTÉRIO DAS CIDADES. Disponível em: <http://www.cidades.gov.br/>. Acesso em: 12 mar. 2015.

NOZAKI, V. T. Análise do setor de saneamento básico no Brasil. 2007. 110f. Dissertação (Mestrado em Economia Aplicada) - Universidade de São Paulo, Ribeirão Preto - SP.

ORGANIZAÇÃO MUNDIAL DA SAÚDE. Disponível em: <http://www.who.int/countries/bra/es/>. Acesso em: 20 mar. 2015.

PROCÓPIO, D. P.; MAIA, M. S.; TOYOSHIMA, S. H.; GOMES, A. P. Eficiência produtiva das empresas prestadoras de serviços de abastecimento de água e coleta de esgoto nos municípios mineiros. Gestão \& Regionalidade, v. 30, n. 90, p. 50-66, 2014.

SAMPAIO, B.; SAMPAIO, Y. Influências políticas na eficiência de empresas de saneamento brasileiras. Revista de Economia Aplicada, v. 11, n. 3, p. 369386, 2007.

SEROA DA MOTTA, R. As opções de marco regulatório de saneamento no Brasil. Plenarium, n. 3, p. 100-116, 2006.

SISTEMA NACIONAL DE INFORMAÇÕES SOBRE SANEAMENTO. Disponível em:<http://www.snis.gov.br/PaginaCarrega.php?EWRErterterTERTer=29>. Acesso em 15 jan. 2015.

VARGAS, M. C. O negócio da água: debatendo experiências recentes de concessão dos serviços de abastecimento de água e esgotamento sanitário a empresas privadas no Brasil. Cuadernos del Cendes, v. 22, n. 59, p. 69-88, 2005.

VARIAN, H. R. Microeconomia conceitos básicos. Rio de Janeiro: Editora Elsevier, 2003. 
Apêndice - 1

Tabela 1A. Resultados encontrados na pesquisa

\begin{tabular}{|c|c|c|c|c|c|}
\hline Cidade & População & Tipo de Empresa & ET & EE & $\begin{array}{ll}\text { Tipo } & \text { de } \\
\text { retorno } & \end{array}$ \\
\hline Aguaí & 32.148 & APD & 0,758 & 0,813 & Decrescente \\
\hline Águas de Lindóia & 17.266 & Autarquia & 0,271 & 0,771 & Decrescente \\
\hline Altinópolis & 15.607 & APD & 0,430 & 0,830 & Decrescente \\
\hline Álvares Florence & 3.897 & Empresa Privada & 1,000 & 0,881 & Crescente \\
\hline Américo Brasiliense & 34.478 & APD & 0,806 & 0,943 & Decrescente \\
\hline Amparo & 65.829 & Autarquia & 0,499 & 0,955 & Crescente \\
\hline Analândia & 4.293 & APD & 0,382 & 0,990 & Decrescente \\
\hline Andradina & 55.334 & Empresa Privada & 0,990 & 0,764 & Decrescente \\
\hline Aparecida & 35.007 & Autarquia & 0,807 & 0,947 & Crescente \\
\hline Araçatuba & 181.579 & Empresa Privada & 1,000 & 0,817 & Decrescente \\
\hline Araçoiaba da Serra & 27.299 & Empresa Privada & 0,850 & 0,996 & Decrescente \\
\hline Araras & 118.843 & Autarquia & 0,724 & 0,672 & Crescente \\
\hline Artur Nogueira & 44.177 & Autarquia & 0,667 & 0,864 & Crescente \\
\hline Atibaia & 126.603 & Autarquia & 0,955 & 0,977 & Decrescente \\
\hline Avanhandava & 11.310 & Autarquia & 0,648 & 0,984 & Decrescente \\
\hline Bady Bassitt & 14.603 & APD & 0,709 & 0,818 & Crescente \\
\hline Barbosa & 6.593 & APD & 0,339 & 0,987 & Crescente \\
\hline Barra Bonita & 35.246 & Autarquia & 0,516 & 0,820 & Decrescente \\
\hline Barretos & 112.101 & Autarquia & 0,810 & 0,698 & Decrescente \\
\hline Barrinha & 28.496 & APD & 0,988 & 0,968 & Crescente \\
\hline Batatais & 56.476 & APD & 0,774 & 0,809 & Decrescente \\
\hline Bebedouro & 75.035 & Autarquia & 0,849 & 0,540 & Decrescente \\
\hline Bilac & 7.048 & APD & 1,000 & 0,943 & Decrescente \\
\hline Birigui & 108.728 & APD & 0,854 & 0,768 & Crescente \\
\hline Bom Jesus dos Perdões & 18.708 & APD & 0,489 & 0,953 & Decrescente \\
\hline Borebi & 2.293 & APD & 0,535 & 0,813 & Crescente \\
\hline Braúna & 5.021 & Autarquia & 0,583 & 0,891 & Crescente \\
\hline Brodowski & 21.107 & Autarquia & 0,696 & 0,976 & Decrescente \\
\hline Brotas & 21.580 & Autarquia & 0,461 & 0,874 & Crescente \\
\hline Buritama & 15.418 & Autarquia & 0,704 & 0,950 & Crescente \\
\hline Cabrália Paulista & 4.365 & APD & 0,404 & 0,968 & Crescente \\
\hline Caconde & 18.538 & APD & 0,501 & 0,954 & Crescente \\
\hline Cafelândia & 16.607 & APD & 0,618 & 0,798 & Crescente \\
\hline Caiuá & 5.039 & APD & 1,000 & 0,745 & Crescente \\
\hline Cajobi & 9.768 & APD & 0,766 & 0,941 & constante \\
\hline Cândido Mota & 29.608 & Autarquia & 0,550 & 0,711 & Crescente \\
\hline Capivari & 48.576 & Autarquia & 0,587 & 0,927 & Decrescente \\
\hline Casa Branca & 28.307 & APD & 0,534 & 0,839 & Crescente \\
\hline Castilho & 18.003 & APD & 0,716 & 0,991 & Crescente \\
\hline Catanduva & 112.820 & Autarquia & 1,000 & 0,750 & Crescente \\
\hline Cedral & 7.972 & APD & 0,551 & 0,976 & Crescente \\
\hline Cerqueira César & 17.532 & APD & 0,953 & 0,995 & Decrescente \\
\hline Cerquilho & 39.617 & Autarquia & 0,581 & 0,850 & Decrescente \\
\hline Chavantes & 12.114 & Autarquia & 0,936 & 0,939 & Crescente \\
\hline Colina & 17.371 & APD & 0,412 & 0,857 & Crescente \\
\hline Conchal & 25.229 & APD & 0,702 & 0,987 & Crescente \\
\hline Cordeirópolis & 21.080 & Autarquia & 0,619 & 0,912 & Constante \\
\hline Corumbataí & 3.874 & APD & 0,399 & 0,869 & Crescente \\
\hline Cosmópolis & 58.827 & APD & 0,942 & 0,736 & Crescente \\
\hline Cosmorama & 7.214 & APD & 0,730 & 0,982 & Decrescente \\
\hline Cravinhos & 31.691 & Autarquia & 0,608 & 0,888 & Crescente \\
\hline Cristais Paulista & 7.588 & APD & 0,741 & 0,938 & Crescente \\
\hline Cruzeiro & 77.039 & Autarquia & 0,722 & 0,784 & Decrescente \\
\hline Descalvado & 31.056 & APD & 0,641 & 0,759 & Decrescente \\
\hline Diadema & 386.089 & SEMAP & 1,000 & 1,000 & Constante \\
\hline Dobrada & 7.939 & APD & 0,782 & 0,894 & Decrescente \\
\hline Dois Córregos & 24.761 & Autarquia & 0,630 & 0,940 & Crescente \\
\hline Dracena & 43.258 & Empresa Pública & 0,671 & 0,862 & Decrescente \\
\hline
\end{tabular}




\begin{tabular}{|c|c|c|c|c|c|}
\hline Dumont & 8.143 & APD & 0,493 & 0,996 & Crescente \\
\hline Engenheiro Coelho & 15.721 & Autarquia & 0,596 & 0,941 & Crescente \\
\hline Estiva Gerbi & 10.044 & APD & 0,583 & 0,991 & Decrescente \\
\hline Garça & 43.115 & Autarquia & 0,603 & 0,944 & Crescente \\
\hline Getulina & 10.765 & APD & 0,415 & 0,998 & Crescente \\
\hline Guaiçara & 10.670 & APD & 0,638 & 0,988 & Crescente \\
\hline Guaimbê & 5.425 & APD & 0,795 & 0,908 & Decrescente \\
\hline Guaíra & 37.404 & Autarquia & 0,667 & 0,789 & Decrescente \\
\hline Guapiaçu & 17.869 & APD & 1,000 & 1,000 & Crescente \\
\hline Guará & 19.858 & Empresa Privada & 0,751 & 0,993 & Decrescente \\
\hline Guaraçaí & 8.435 & Autarquia & 0,520 & 0,988 & Crescente \\
\hline Guaraci & 9976 & APD & 0,769 & 0,914 & Decrescente \\
\hline Guararapes & 30.597 & APD & 0,729 & 0,857 & Crescente \\
\hline Guaratinguetá & 112.072 & SEMAP & 0,523 & 0,897 & Decrescente \\
\hline Guatapará & 6.966 & APD & 0,677 & 0,953 & Crescente \\
\hline Herculândia & 8.696 & APD & 0,649 & 0,997 & Crescente \\
\hline lacanga & 10.013 & APD & 0,673 & 0,995 & Crescente \\
\hline Ibirarema & 6.725 & Autarquia & 0,656 & 0,951 & Crescente \\
\hline Ibitinga & 53.158 & Autarquia & 0,537 & 0,866 & Crescente \\
\hline lepê & 7.628 & APD & 0,740 & 0,971 & Crescente \\
\hline Igaraçu do Tietê & 23.362 & APD & 0,476 & 0,929 & Crescente \\
\hline Ilha Solteira & 25.064 & APD & 0,552 & 0,924 & Decrescente \\
\hline Indaiatuba & 201.619 & Autarquia & 0,787 & 0,793 & Crescente \\
\hline Ipaussu & 13.663 & APD & 0,958 & 0,943 & Decrescente \\
\hline Iperó & 28.300 & APD & 0,752 & 0,989 & Crescente \\
\hline Ipeúna & 6.016 & APD & 0,628 & 0,988 & Decrescente \\
\hline Ipuã & 14.148 & Autarquia & 0,566 & 0,996 & Crescente \\
\hline Iracemápolis & 20.029 & APD & 1,000 & 1,000 & Crescente \\
\hline Itajobi & 14.556 & APD & 0,713 & 0,961 & Crescente \\
\hline Itaju & 3.246 & APD & 1,000 & 0,782 & Crescente \\
\hline Itapira & 68.537 & Autarquia & 0,666 & 0,818 & Crescente \\
\hline Itápolis & 40.051 & Autarquia & 0,780 & 0,848 & Constante \\
\hline Itapuí & 12.173 & APD & 0,629 & 0,998 & Constante \\
\hline Itirapina & 15.527 & APD & 0,700 & 0,994 & Decrescente \\
\hline Itu & 154.147 & Empresa Privada & 0,583 & 0,854 & Constante \\
\hline Ituverava & 38.695 & Autarquia & 0,551 & 0,773 & Decrescente \\
\hline Jaboticabal & 71.662 & Autarquia & 0,683 & 0,886 & Crescente \\
\hline Jacareí & 211.214 & Autarquia & 0,714 & 0,875 & Decrescente \\
\hline Jaci & 5.657 & APD & 0,731 & 0,886 & Crescente \\
\hline Jaguariúna & 44.311 & APD & 0,537 & 0,873 & Crescente \\
\hline Jardinópolis & 37.661 & APD & 0,891 & 0,724 & Crescente \\
\hline Jaú & 131.040 & Autarquia & 0,511 & 0,804 & Crescente \\
\hline João Ramalho & 4.150 & APD & 1,000 & 1,000 & Crescente \\
\hline José Bonifácio & 32.763 & APD & 0,882 & 0,641 & Crescente \\
\hline Jumirim & 2.798 & APD & 1,000 & 0,605 & Crescente \\
\hline Junqueirópolis & 18.726 & APD & 0,719 & 0,687 & Crescente \\
\hline Lavínia & 8.779 & APD & 0,696 & 0,849 & Decrescente \\
\hline Leme & 91.756 & Autarquia & 0,665 & 0,810 & Decrescente \\
\hline Lençóis Paulista & 61.428 & Autarquia & 0,714 & 0,826 & Crescente \\
\hline Lindóia & 6.712 & APD & 1,000 & 0,861 & Crescente \\
\hline Louveira & 37.125 & APD & 0,687 & 0,855 & Decrescente \\
\hline Luís Antônio & 11.286 & APD & 0,829 & 0,962 & Crescente \\
\hline Macaubal & 7.663 & APD & 0,434 & 0,998 & Decrescente \\
\hline Mairinque & 43.223 & Empresa Privada & 0,758 & 0,999 & Crescente \\
\hline Manduri & 8.992 & Autarquia & 0,622 & 0,969 & Crescente \\
\hline Marapoama & 2.633 & APD & 0,433 & 0,954 & Decrescente \\
\hline Marília & 21.6745 & Autarquia & 0,858 & 0,765 & Crescente \\
\hline Martinópolis & 24.219 & APD & 0,688 & 0,946 & Crescente \\
\hline Matão & 76.786 & Autarquia & 0,544 & 0,774 & Decrescente \\
\hline Mendonça & 4.640 & APD & 0,754 & 0,979 & Constante \\
\hline Mineiros do Tietê & 12.038 & APD & 0,723 & 0,983 & Decrescente \\
\hline Mirandópolis & 27.483 & APD & 0,605 & 0,821 & Decrescente \\
\hline Mirassol & 53.792 & Empresa Privada & 0,839 & 0,726 & Crescente \\
\hline Mogi das Cruzes & 387.779 & Autarquia & 1,000 & 0,924 & Decrescente \\
\hline
\end{tabular}




\begin{tabular}{|c|c|c|c|c|c|}
\hline Mogi Guaçu & 137.245 & Autarquia & 0,717 & 0,808 & Crescente \\
\hline Mogi Mirim & 86.505 & Autarquia & 0,545 & 0,863 & Crescente \\
\hline Monte Alegre do Sul & 7.152 & APD & 0,753 & 0,924 & Decrescente \\
\hline Monte Azul Paulista & 18.931 & APD & 0,667 & 0,971 & Crescente \\
\hline Monte Castelo & 4.063 & APD & 0,548 & 0,931 & Constante \\
\hline Morro Agudo & 29.116 & APD & 0,556 & 0,951 & Decrescente \\
\hline Motuca & 4.290 & APD & 0,897 & 0,866 & Crescente \\
\hline Murutinga do Sul & 4.186 & APD & 0,653 & 0,840 & Crescente \\
\hline Nantes & 2.707 & APD & 0,366 & 0,963 & Decrescente \\
\hline Nova Independência & 3.068 & APD & 0,508 & 0,938 & Decrescente \\
\hline Novais & 4.592 & APD & 1,000 & 0,648 & Decrescente \\
\hline Nova Odessa & 51.242 & SEMAP & 0,601 & 0,833 & Decrescente \\
\hline Nuporanga & 6.817 & APD & 0,442 & 0,938 & Decrescente \\
\hline Ocauçu & 4.163 & APD & 1,000 & 0,720 & Decrescente \\
\hline Olímpia & 50.024 & Autarquia & 0,741 & 0,856 & Crescente \\
\hline Orlândia & 39.781 & APD & 0,657 & 0,864 & Decrescente \\
\hline Ourinhos & 103.035 & Autarquia & 0,498 & 0,853 & Decrescente \\
\hline Ouro Verde & 7.800 & APD & 0,663 & 0,981 & Decrescente \\
\hline Pacaembu & 13.226 & APD & 0,535 & 0,985 & Crescente \\
\hline Palestina & 11.051 & Empresa Privada & 0,659 & 0,996 & Decrescente \\
\hline Palmital & 21.186 & Autarquia & 0,629 & 0,971 & Decrescente \\
\hline Panorama & 14.583 & APD & 0,665 & 0,998 & Decrescente \\
\hline Paraibuna & 17.388 & APD & 0,452 & 0,801 & Decrescente \\
\hline Parisi & 2.032 & APD & 1,000 & 0,516 & Decrescente \\
\hline Patrocínio Paulista & 13.000 & APD & 0,411 & 0,991 & Decrescente \\
\hline Pedreira & 41.558 & Autarquia & 0,375 & 0,871 & Decrescente \\
\hline Penápolis & 58.510 & Autarquia & 0,759 & 0,822 & Crescente \\
\hline Pereira Barreto & 24.962 & Autarquia & 0,681 & 0,969 & Decrescente \\
\hline Pereiras & 7.454 & APD & 0,455 & 0,984 & Decrescente \\
\hline Pindorama & 15.039 & APD & 0,839 & 0,997 & Decrescente \\
\hline Piquete & 14.107 & Empresa Privada & 1,000 & 0,974 & Decrescente \\
\hline Pirajuí & 22.704 & Autarquia & 0,667 & 0,961 & Crescente \\
\hline Pirangi & 10.623 & APD & 0,585 & 0,987 & Decrescente \\
\hline Pirassununga & 70.081 & Autarquia & 0,503 & 0,865 & Decrescente \\
\hline Pitangueiras & 35.307 & APD & 1,000 & 1,000 & Crescente \\
\hline Pontal & 40.244 & APD & 1,000 & 1,000 & Crescente \\
\hline Porto Feliz & 48.893 & Autarquia & 0,570 & 0,950 & Decrescente \\
\hline Porto Ferreira & 51.400 & Empresa privada & 0,692 & 0,795 & Decrescente \\
\hline Potirendaba & 15.449 & APD & 0,639 & 0,792 & Crescente \\
\hline Pradópolis & 17.377 & APD & 0,843 & 1,000 & Decrescente \\
\hline Presidente Venceslau & 37.910 & APD & 0,698 & 0,820 & Decrescente \\
\hline Promissão & 35.674 & Autarquia & 0,632 & 0,894 & Decrescente \\
\hline Rafard & 8.612 & APD & 0,315 & 0,962 & Decrescente \\
\hline Rancharia & 28.804 & APD & 0,653 & 0,843 & Decrescente \\
\hline Reginópolis & 7.323 & APD & 0,393 & 0,996 & Decrescente \\
\hline Rincão & 10.414 & APD & 0,523 & 0,991 & Decrescente \\
\hline Rio das Pedras & 29.501 & Autarquia & 0,588 & 0,927 & Decrescente \\
\hline Sabino & 5.217 & APD & 0,696 & 0,956 & Crescente \\
\hline Saltinho & 7.059 & APD & 0,380 & 0,981 & Decrescente \\
\hline Salto & 10.516 & Autarquia & 0,624 & 0,819 & Decrescente \\
\hline Salto Grande & 8.787 & APD & 0,625 & 0,988 & Decrescente \\
\hline Santa Adélia & 14.333 & APD & 0,946 & 0,963 & Decrescente \\
\hline Santa Bárbara D Oeste & 180.009 & Autarquia & 0,680 & 0,814 & Decrescente \\
\hline Santa Branca & 13.763 & APD & 0,860 & 0,919 & Decrescente \\
\hline Santa Cruz da Conceição & 4.002 & APD & 0,381 & 0,982 & Decrescente \\
\hline Santa Cruz das Palmeiras & 29.932 & APD & 0,949 & 0,911 & Decrescente \\
\hline Santa Fé do Sul & 29.239 & Autarquia & 0,576 & 0,874 & Decrescente \\
\hline Santa Gertrudes & 21.634 & Empresa Privada & 0,755 & 0,995 & Decrescente \\
\hline Santa Isabel & 50.453 & APD & 0,962 & 0,983 & Decrescente \\
\hline Santa Lúcia & 8.248 & APD & 0,622 & 0,989 & Decrescente \\
\hline Santa Rita D Oeste & 2.543 & APD & 0,767 & 0,659 & Decrescente \\
\hline Santa Rita do Passa Quatro & 26.478 & APD & 0,703 & 0,869 & Decrescente \\
\hline Santo Antônio da Alegria & 6.304 & APD & 0,517 & 0,968 & Decrescente \\
\hline Santo Antônio de Posse & 20.650 & APD & 0,749 & 0,978 & Decrescente \\
\hline
\end{tabular}




\begin{tabular}{|c|c|c|c|c|c|}
\hline Santo Antônio do Aracanguá & 7.626 & APD & 0,614 & 0,941 & Decrescente \\
\hline São Caetano do Sul & 149.263 & Autarquia & 0,680 & 0,925 & Decrescente \\
\hline São Carlos & 221.950 & Autarquia & 0,954 & 0,638 & Decrescente \\
\hline São João de Iracema & 1.780 & APD & 0,907 & 0,481 & Decrescente \\
\hline São Joaquim da Barra & 46.512 & APD & 0,921 & 0,801 & Decrescente \\
\hline São José da Bela Vista & 8.406 & APD & 0,898 & 0,953 & Decrescente \\
\hline São José do Barreiro & 4.077 & APD & 1,000 & 0,930 & Crescente \\
\hline São José do Rio Pardo & 51.900 & APD & 0,880 & 0,873 & Decrescente \\
\hline São Pedro & 31.662 & Autarquia & 0,597 & 0,972 & Decrescente \\
\hline São Pedro do Turvo & 7.198 & Autarquia & 0,793 & 0,876 & Crescente \\
\hline São Sebastião da Grama & 12.099 & APD & 0,519 & 0,999 & Decrescente \\
\hline São Simão & 14.346 & APD & 0,686 & 0,996 & Decrescente \\
\hline Serrana & 38.878 & APD & 1,000 & 0,969 & Decrescente \\
\hline Sertãozinho & 110.074 & Autarquia & 0,637 & 0,872 & Crescente \\
\hline Sumaré & 241.311 & Autarquia & 0,869 & 0,757 & Decrescente \\
\hline Suzanápolis & 3.383 & APD & 1,000 & 0,946 & Decrescente \\
\hline Tabapuã & 11.363 & APD & 0,417 & 0,881 & Crescente \\
\hline Taiaçu & 5.894 & APD & 0,818 & 0,865 & Decrescente \\
\hline Taiúva & 5.447 & APD & 0,432 & 0,939 & Crescente \\
\hline Tambaú & 22.406 & APD & 0,541 & 0,84 & Decrescente \\
\hline Tanabi & 24.055 & Autarquia & 0,876 & 0,988 & Decrescente \\
\hline Taquaritinga & 53.988 & Autarquia & 0,671 & 0,829 & Crescente \\
\hline Tejupá & 4.809 & APD & 0,519 & 0,932 & Decrescente \\
\hline Tietê & 36.835 & Autarquia & 0,683 & 0,969 & Decrescente \\
\hline Trabiju & 1.544 & APD & 0,436 & 1,000 & constante \\
\hline Tupi Paulista & 14.269 & APD & 0,622 & 0,997 & Decrescente \\
\hline Uchoa & 9.471 & APD & 0,562 & 0,994 & Crescente \\
\hline Urupês & 12.714 & APD & 0,868 & 0,955 & Crescente \\
\hline Valinhos & 106.793 & Autarquia & 0,564 & 0,674 & Decrescente \\
\hline Valparaíso & 22.576 & Autarquia & 0,568 & 0,997 & Crescente \\
\hline Vargem Grande do Sul & 39.266 & Autarquia & 0,567 & 0,695 & Decrescente \\
\hline Vinhedo & 63.611 & Autarquia & 0,420 & 0,962 & Decrescente \\
\hline Viradouro & 17.297 & Autarquia & 0,626 & 0,998 & Constante \\
\hline Votorantim & 108.809 & Empresa Privada & 0,559 & 0,898 & Decrescente \\
\hline Votuporanga & 84.692 & Autarquia & 0,668 & 0,770 & Decrescente \\
\hline
\end{tabular}

